Cite this: Phys. Chem. Chem. Phys., 2014, 16, 8257

Received 20th November 2013, Accepted 14th March 2014

DOI: $10.1039 / c 3 c p 54917 h$

www.rsc.org/pccp

\section{Solid state chemistry of nitrogen oxides - Part I: surface consumption of NO}

\author{
M. Minissale, ${ }^{\star a}$ G. Fedoseev, $^{b}$ E. Congiu, ${ }^{a}$ S. Ioppolo, ${ }^{\text {cd }}$ F. Dulieu ${ }^{a}$ and H. Linnartz ${ }^{b}$
}

The role of nitrogen and oxygen chemistry in the interstellar medium is still rather poorly understood. Nitric oxide, NO, has been proposed as an important precursor in the formation of larger $\mathrm{N}$ - and $\mathrm{O}$-bearing species, such as hydroxylamine, $\mathrm{NH}_{2} \mathrm{OH}$, and nitrogen oxides, $\mathrm{NO}_{2}$ and $\mathrm{N}_{2} \mathrm{O}$. The topic of this study is the solid state consumption of $\mathrm{NO}$ via oxygenation and the formation of $\mathrm{NO}_{2}$ and other nitrogen oxides $\left(\mathrm{ONNO}_{2}\right.$ and $\left.\mathrm{N}_{2} \mathrm{O}_{4}\right)$ under conditions close to those encountered on icy grains in quiescent interstellar clouds. In our experiments nitric oxide and oxygen allotropes $\left(\mathrm{O}_{2} \mathrm{O}_{2}\right.$, and $\left.\mathrm{O}_{3}\right)$ or $\mathrm{N}$ atoms are co-deposited under ultra-high vacuum conditions on different substrates (silicate, graphite, compact ASW ice, and gold) at temperatures ranging between 10 and $35 \mathrm{~K}$. Reaction products are monitored via Fourier Transform Reflection Absorption Infrared Spectroscopy (FT-RAIRS) and Temperature Programmed Desorption (TPD) using mass spectrometry. We find that $\mathrm{NO}_{2}$ is efficiently formed in $\mathrm{NO}+\mathrm{O} / \mathrm{O}_{2} / \mathrm{O}_{3} / \mathrm{N}$ solid surface reactions. These are essentially barrier free and offer a pathway for the formation of $\mathrm{NO}_{2}$ in space. Nitrogen dioxide, however, has not been astronomically detected, contradicting the efficient reaction channel found here. This is likely due to other pathways, including regular hydrogenation reactions, as discussed separately in part II of this study.

\section{Introduction}

Dark interstellar clouds act as birth sites of stars and planets, in which a complex network of sequential and parallel chemical processes, both in the gas phase and in the solid state, leads to the formation of larger molecules. Since gas-phase reactions alone cannot explain the full molecular complexity observed in space, it is generally accepted that more complex and saturated species form in the solid state through energetic (heating or hits by UV photons, X-rays, electrons or ions) and non-energetic (atom bombardment) processing. ${ }^{1}$ Indeed, deep within dark clouds, temperatures drop as low as $10 \mathrm{~K}$ and with densities higher than $10^{5} \mathrm{~cm}^{-3}, 2$ gas species accrete onto grains forming icy mantles. These regions are shielded from external UV light (other than local Ly- $\alpha$ emission from cosmic rays excited hydrogen) and the chemistry is largely driven by the impact of free atoms on icy dust. Atoms and unsaturated species diffuse in the ice, meet, and eventually react thermally or through

\footnotetext{
${ }^{a}$ LERMA-LAMAp, Université de Cergy-Pontoise, Observatoire de Paris, ENS, UPMC, UMR 8112 du CNRS, 5 Mail Gay Lussac, 95000 Cergy Pontoise Cedex, France. E-mail: marco.minissale@obspm.fr

${ }^{b}$ Raymond and Beverly Sackler Laboratory for Astrophysics, Leiden Observatory, Leiden University, P.O. Box 9513, 2300 RA Leiden, The Netherlands

${ }^{c}$ Division of Geological and Planetary Sciences, California Institute of Technology, 1200 E. California Blvd., Pasadena, California 91125, USA

${ }^{d}$ Institute for Molecules and Materials, Radboud University Nijmegen,

P.O. Box 9010, 6500 GL Nijmegen, The Netherlands
}

tunneling $^{3-6}$ with the grain acting as a third body absorbing excess energy. Many of the bulk molecules observed in interstellar ice (e.g. , $\mathrm{H}_{2} \mathrm{O}, \mathrm{CO}_{2}, \mathrm{H}_{2} \mathrm{CO}, \mathrm{CH}_{3} \mathrm{OH}, \mathrm{HCOOH}, \mathrm{CH}_{4}, \mathrm{NH}_{3}$, and other nitrogen-bearing species ${ }^{7-11}$ ) form in this way. In later stages of the star formation process (i.e., when the protostar has formed), the local UV field gains intensity and energetic processing becomes important, contributing also to molecular complexity in space. ${ }^{12-14}$

Over the past decade, a number of independent laboratory experiments have been performed to study surface reactions involving hydrogen, oxygen, carbon, and nitrogen atoms on cold surfaces. ${ }^{15-22}$ The focus in these studies has been largely on hydrogen and oxygen chemistry, characterizing the solid state formation of water and methanol, for example. More recently a number of studies involving nitrogen have also been reported. ${ }^{23}$ The solid state formation of $\mathrm{NH}_{3}$ has been discussed ${ }^{24}$ and NO ice was shown to be a good starting point in the formation of hydroxylamine, upon $\mathrm{H}$-atom additions. ${ }^{25-27}$ Both nitric oxide and ammonia are considered important precursor species in the formation of $\mathrm{N}$-containing organics. $\mathrm{NO}$, specifically, is a seed for $\mathrm{N}$ - and O-bearing species ${ }^{28}$ such as $\mathrm{NO}_{2}, \mathrm{~N}_{2} \mathrm{O}, \mathrm{HNO}$, $\mathrm{HONO}, \mathrm{HNO}_{3}$, and $\mathrm{NH}_{2} \mathrm{OH}$.

$\mathrm{NO}\left({ }^{14} \mathrm{~N}^{16} \mathrm{O}\right)$ was initially identified in the molecular clouds Sgr $\mathrm{B} 2{ }^{29}$ and OMC1. ${ }^{30}$ Nitric oxide has been identified in a number of different astrophysical regions, including star forming regions, ${ }^{30}$ dark clouds, ${ }^{31-33}$ hot cores, ${ }^{34}$ PDRs, ${ }^{35}$ and in the nucleus of the starburst galaxy NGC 253 - an extragalactic source. ${ }^{36}$ NO can be 
easily formed and destroyed by two neutral-neutral gas-phase reactions: ${ }^{37}$

$$
\begin{aligned}
& \bullet \mathrm{N}+\mathrm{OH} \rightarrow \mathrm{NO}+\mathrm{H} \\
& -\mathrm{NO}+\mathrm{N} \rightarrow \mathrm{N}_{2}+\mathrm{O} .
\end{aligned}
$$

Laboratory experiments have shown that NO is also formed through surface reactions, upon exposure of different ice mixtures (i.e., $\mathrm{H}_{2} \mathrm{O}: \mathrm{N}_{2}, \mathrm{CO}: \mathrm{N}_{2}$, and $\left.\mathrm{N}_{2}: \mathrm{O}_{2}\right)$ to different ions $\left({ }^{13} \mathrm{C}^{2+}, \mathrm{Ar}^{2+}\right.$, $\mathrm{N}^{+}$and $\mathrm{H}^{+}$, respectively) with energies in the range between $15-200 \mathrm{keV}^{38-40}$ So far no evidence has been found that NO forms in non-energetic surface reactions like, for example, $\mathrm{N}+\mathrm{O}$. Astrochemical models predict typical NO abundances in the gas-phase, with respect to molecular hydrogen, of $f\left(\mathrm{NO} / \mathrm{H}_{2}\right) \approx 10^{-7}-10^{-6}$. The actual observed abundance ${ }^{41}$ is about a factor 10 lower: $f\left(\mathrm{NO} / \mathrm{H}_{2}\right) \approx 10^{-8}$. This difference may be due to lacking destruction (i.e., consumption) routes that have not taken correctly into account; actually large amounts of NO (up to $10 \%$ of the gas-phase abundance) are likely to accrete on the cold $(10 \mathrm{~K})$ dust grains, and therefore to react with $\mathrm{H}, \mathrm{O}$, and $\mathrm{N}$ atoms arriving from the gas-phase. It is not straightforward to estimate the relevance of solid $\mathrm{NO}$ as a starting point for the formation of more complex species. Reactions of NO with O-atoms have not been experimentally studied yet and this is the topic of the present study.

In this paper, part I in a two-article series, we present experimental results for $\mathrm{NO}+\mathrm{O}, \mathrm{NO}+\mathrm{O}_{2}, \mathrm{NO}+\mathrm{O}_{3}$, and $\mathrm{NO}+\mathrm{N}$ reactions in the solid state that mainly lead to the formation of $\mathrm{NO}_{2}$. Part II focusses on the surface consumption of $\mathrm{NO}_{2}$ through $\mathrm{NO}_{2}+\mathrm{H} / \mathrm{O} / \mathrm{N}$. This paper is organized as follows. The experimental setup and methods are described in the next section. Section 3 presents the experimental results. Section 4 discusses the possible reaction routes and physical chemistry of the $\mathrm{N}-\mathrm{O}$ world. The findings are summarized in the conclusion.

\section{Experimental}

The experiments are performed using two different setups: FORMOLISM located in the LERMA-LAMAp laboratory at the University of Cergy-Pontoise (FR) ${ }^{25}$ and SURFRESIDE ${ }^{2}$ at the Sackler Laboratory for Astrophysics in Leiden (NL). ${ }^{42}$ The possibility to perform similar experiments in two different setups allows us to study the same reaction pathways under different physical conditions, i.e., different surface coverage (sub-monolayers mainly FORMOLISM vs. multilayers - mainly SURFRESIDE ${ }^{2}$ ), different substrates (gold, silicates, graphite and amorphous solid water (ASW) ice), and different ice mixtures (pure NO, NO in polar ice, and NO in apolar ice).

Both setups comprise a central ultra-high vacuum chamber in which a sample holder is mounted in thermal contact with the cold finger of a closed-cycle He cryostat. The ice samples are studied in situ using Fourier Transform Reflection Absorption Infrared Spectroscopy (FT-RAIRS) and thermally relieved species are monitored in the gas phase by Temperature Programmed Desorption (TPD) using quadrupole mass spectrometry (QMS).
Two different experimental procedures are applied. In predeposition experiments, ice is first deposited on the substrate and then exposed to the beam with reactants. This approach is necessary for $\mathrm{O}_{3}$ as it is not possible to work with a pure ozone beam. Instead pure $\mathrm{O}_{3}$ ice is obtained through annealing, causing other constituents than ozone to thermally desorb. ${ }^{43,44,57,58}$ In pre-deposition experiments $\mathrm{NO}$ is subsequently deposited on top of the pure $\mathrm{O}_{3}$ ice. In the case of $\mathrm{O}$ and $\mathrm{O}_{2}$ experiments, all the reactants, including NO, are co-deposited. In all the experiments presented in this paper, unless otherwise specified, molecules of the most abundant isotopologues are used $\left({ }^{16} \mathrm{O}_{2}, \mathrm{H}_{2}{ }^{16} \mathrm{O},{ }^{14} \mathrm{~N}^{16} \mathrm{O}\right.$, and $\left.{ }^{14} \mathrm{~N}_{2}{ }^{16} \mathrm{O}\right)$.

RAIR difference spectra are acquired during the exposure of the sample with respect to a background spectrum of the initial deposited ice at low temperature. In the case of co-deposition experiments, nitrogen oxide bearing ices are continuously deposited together with the reactant ices ( $\mathrm{NO}+\mathrm{O}$ and $\mathrm{NO}+\mathrm{O}_{2}$ ). In this case, RAIR difference spectra are acquired during co-deposition with respect to a background spectrum of the bare substrate at a low temperature. Once completed, the ice composition is further constrained using TPD, typically with rates of 1 up to $10 \mathrm{~K} \mathrm{~min}^{-1}$.

As full descriptions of both setups are available in ref. 25 and 42 only the relevant details are given below.

\subsection{FORMOLISM setup}

The main chamber of the FORMOLISM setup ${ }^{25,45}$ has a base pressure of $10^{-10}-10^{-11}$ mbar. It contains a non-porous amorphous olivine-type silicate (or a HOPG) sample surface $(1 \mathrm{~cm}$ in diameter), operating at temperatures between 6.5 and $400 \mathrm{~K}$. The silicate sample was obtained by thermal evaporation of San Carlos olivine $\left(\mathrm{Mg}_{1.8} \mathrm{Fe}_{0.2} \mathrm{SiO}_{4}\right)$ onto a gold-coated substrate $(1 \mathrm{~cm}$ in diameter), operating at temperatures between 6.5 and $350 \mathrm{~K}$. The density sites of adsorption are about the same as those of compact ice samples. Sample preparation and surface analysis are described extensively in Djouadi et al. (2005). ${ }^{46}$ The temperature is controlled using a calibrated silicon-diode sensor and a thermocouple (AuFe/Chromel K-type) clamped to the sample holder. ASW ice can be grown in situ on the silicate sample. The $\mathrm{H}_{2} \mathrm{O}$ vapour is obtained from deionized water previously purified by several freeze-pump-thaw cycles carried out under vacuum. $\mathrm{H}_{2} \mathrm{O}$ molecules are deposited on the surface maintained at $110 \mathrm{~K}$ through a leak valve equipped with a microchannel doser positioned at $3.5 \mathrm{~cm}$ in front of the cold surface during the water ice deposition phase.

Two triply differentially pumped beam-lines are used to (co)deposit the reactants ( $\mathrm{NO}$ and $\mathrm{O}, \mathrm{O}_{2}, \mathrm{or}_{3}$ ) onto the surface of the sample holder. Each beam line is equipped with a microwave dissociation source (a Surfatron cavity delivering $300 \mathrm{~W}$ at $2.45 \mathrm{GHz}$ ) that can generate oxygen atoms (in the ${ }^{3} \mathrm{P}$ ground state) from $\mathrm{O}_{2}$. The $\mathrm{O}_{2}$ dissociation efficiency is $\tau=65-70 \%$. The flux of $\mathrm{O}$ atoms arriving onto the surface is $\phi_{\mathrm{O}}=2 \tau \phi \mathrm{O}_{2}$, where $\phi_{\mathrm{O}_{2}}=$ $3.2( \pm 0.3) \times 10^{12}$ molecules $\mathrm{cm}^{-2} \mathrm{~s}^{-1}$ is the flux of $\mathrm{O}_{2}$ molecules. ${ }^{61}$ The flux of $\mathrm{O}$ atoms, consequently, is estimated to be $4.4( \pm 0.4) \times 10^{12}$ atoms $\mathrm{cm}^{-2} \mathrm{~s}^{-1}$. The (direct) flux of NO molecules at the surface is $2.8( \pm 0.2) \times 10^{12}$ molecules $\mathrm{cm}^{-2} \mathrm{~s}^{-1}$. 


\subsection{SURFRESIDE $^{2}$ setup}

SURFRESIDE $^{2}$ comprises three distinct UHV chambers: a main chamber and two beam lines. Base pressures are better than $10^{-10}$ mbar. In the main chamber, ices can be deposited with monolayer precision on a gold substrate and processed at astronomically relevant temperatures. The substrate temperature is varied between 12 and $300 \mathrm{~K}$ with a relative precision of $0.5 \mathrm{~K}$ through a cryogenic temperature controller (LakeShore model 340). Ices are monitored in situ by means of RAIRS using a commercial FTIR, which covers the range between 4000 and $700 \mathrm{~cm}^{-1}(2.5-14 \mu \mathrm{m})$. TPD is used as a complementary analytical tool to constrain the experimental results. In the two beam lines different atom sources are used to produce atoms and radicals: (i) a thermal cracking source ${ }^{47-49}$ is used to generate controlled beams of $\mathrm{H} / \mathrm{D}$ atoms and (ii) a microwave discharge source ${ }^{50,51}$ is used to generate $\mathrm{O}$ atoms that are co-deposited with NO-containing mixtures onto the substrate. This source has a $2.45 \mathrm{GHz}$ microwave power supply (Sairem) that produces up to $300 \mathrm{~W}$ of power that is coupled into a microwave cavity, where atoms are generated in a plasma. All electronically and ro-vibrationally excited species generated in the plasma are energetically quenched through multiple collisions on passing through a quartz pipe before reaching the sample surface. Different plasma cavity pressures and/or different plasma power values give access to a tunable range of atom fluxes covering roughly $10^{11}$ and $10^{13}$ atoms $\mathrm{cm}^{-2} \mathrm{~s}^{-1}$. In the present experiment, $\mathrm{O}$ and $\mathrm{N}$ atoms are obtained from $\mathrm{N}_{2} \mathrm{O}$ and $\mathrm{N}_{2}$ dissociation, respectively (see ref. 42). The effective $\mathrm{O}-$ and N-atom flux at the surface are $1( \pm 0.3) \times 10^{11}$ and $9 \times 10^{10}$ atoms $\mathrm{cm}^{-2} \mathrm{~s}^{-1}$, respectively. Shutters separate the beam line chambers from the main chamber and allow for an independent operation of the individual beam lines.

In the following sections the experiments are not specifically labeled as FORMOLISM or SURFRESIDE ${ }^{2}$ based, instead an overview of all experiments performed is given in Table 1.

\section{Results}

Fig. 1 shows four TPD curves of NO (mass 30, left-panel) and $\mathrm{NO}_{2}$ (mass 46, right-panel) as obtained after completion of different experiments in the (sub)monolayer (ML) regime: 0.4 ML NO (black curve), 0.4 ML NO + 1.5 ML O (red curve), $0.4 \mathrm{ML} \mathrm{NO}+1.5 \mathrm{ML} \mathrm{O}_{2}$ (green curve), and 0.4 $\mathrm{ML} \mathrm{NO}+1.5 \mathrm{ML} \mathrm{O}_{3}$ (blue curve) on a silicate sample held at $10 \mathrm{~K}$. In our experiments, the desorption of NO takes place between 43 and $60 \mathrm{~K}$, while $\mathrm{NO}_{2}$ desorbs between 110 and $140 \mathrm{~K}$. The left panel of Fig. 1 clearly shows that NO is consumed when oxygenated. In particular, when $\mathrm{O}$ atoms are co-deposited with NO molecules, they react and less than $10 \%$ of NO remains. This is about $40 \%$ in the case of $\mathrm{O}_{3}$ molecules, while in the case of $\mathrm{O}_{2}$ up to $70 \%$ of $\mathrm{NO}$ does not react. In parallel, the integrated area under the $\mathrm{NO}_{2}$ TPD curves in Fig. 1 (right panel) anti-correlates with the corresponding integrated area of the NO TPD curve; a smaller amount of NO left on the cold surface after oxygenation corresponds to a larger amount of $\mathrm{NO}_{2}$ formed in the ice.
In the next section we present RAIRS results, separately for $\mathrm{NO}+\mathrm{O}, \mathrm{NO}+\mathrm{O}_{2}, \mathrm{NO}+\mathrm{O}_{3}$, and $\mathrm{NO}+\mathrm{N}$.

\section{1 $\mathrm{NO}+\mathrm{O}$}

The NO + O reaction was studied by co-depositing reactants on different substrates (silicate and gold), and in different ice environments (pure $\mathrm{NO}+\mathrm{O}, \mathrm{NO}: \mathrm{H}_{2} \mathrm{O}+\mathrm{O}$, and $\mathrm{NO}: \mathrm{CO}+\mathrm{O}$ ). In addition, as shown in Table 1 , we performed every single experiment under different coverage conditions. The submonolayer regimes cover from 0.1 to $1 \mathrm{ML}$ and the multilayer regimes are in the range of 1 to $10 \mathrm{ML}$.

As mentioned before, oxygen atoms are obtained via $\mathrm{O}_{2}$ (FORMOLISM) or $\mathrm{N}_{2} \mathrm{O}$ (SURFRESIDE ${ }^{2}$ ) dissociation. In the first case, the $\mathrm{O}_{2}$ dissociation is not complete (65\%), and, therefore, some oxygen molecules may still reach the surface and react with NO. In the second case, undissociated $\mathrm{N}_{2} \mathrm{O}$ molecules are still present, but the probability of forming $\mathrm{O}_{2}$ molecules is very low (see ref. 42). An advantage of using $\mathrm{N}_{2} \mathrm{O}$ is that it does not react with NO (and other nitrogen oxides) or O atoms. ${ }^{42}$

Fig. 2 shows four RAIR spectra recorded for a silicate sample held at $10 \mathrm{~K}$ using $\mathrm{O}_{2}$ dissociation. Curve (a) shows the unprocessed spectrum for 1.5 ML of NO. Curves (b) and (c) show the results of a co-deposition resulting in 1.5 and $3.5 \mathrm{ML}$ thick ice of $\mathrm{NO}+\mathrm{O}+\mathrm{O}_{2}$ in a mixing ratio $(3: 3: 1)$, respectively. Curve (d) shows the spectrum for deposition conditions used in curve (c), but after annealing to $86 \mathrm{~K}$ and cooling down to $50 \mathrm{~K}$.

In curve (a) the NO (dimer) symmetric and asymmetric $\mathrm{N}-\mathrm{O}$ stretch modes can be seen at around 1861 and $1770 \mathrm{~cm}^{-1}$. The other three curves are clearly different with a number of new spectral features. Peaks at 1304-1311 and $1602 \mathrm{~cm}^{-1}$ are due to both $\mathrm{NO}_{2}$ and $\mathrm{ONNO}_{2}$ (i.e., $\mathrm{N}_{2} \mathrm{O}_{3}$ ). Peaks at 1878, 1741 and $1256 \mathrm{~cm}^{-1}$ are due to $\mathrm{N}_{2} \mathrm{O}_{4}$. The peak at $1834 \mathrm{~cm}^{-1}$ is also due to $\mathrm{ONNO}_{2}(\mathrm{~N}=\mathrm{O}$ stretch). This latter peak does not show up in curve (d) indicating that $\mathrm{ONNO}_{2}$ is not present at high temperature $(>80 \mathrm{~K})$. For this reason, in curve $(\mathrm{d})$, we think that peaks at 1304-1311 and $1602 \mathrm{~cm}^{-1}$ are due to $\mathrm{NO}_{2}$ ice. Here annealing offers an additional tool in assigning the bands. For instance, both $\mathrm{NO}$ dimer and $\mathrm{N}_{2} \mathrm{O}_{4}$ can contribute to the bands shown in curve (c) between 1890-1850 and 1755-1730 $\mathrm{cm}^{-1}$. However, since the spectrum in curve $\mathrm{d}$ is obtained after annealing to $86 \mathrm{~K}$ - at this temperature all NO molecules have desorbed - the peaks at 1878 and $1741 \mathrm{~cm}^{-1}$ can only be due to $\mathrm{N}_{2} \mathrm{O}_{4}$. This facilitates the overall assignment of all spectra.

Fig. 3 shows four more RAIR spectra (with two zoom-ins), now explicitly involving water in the $15 \mathrm{~K}$ deposition process simulating a polar environment. In curve (a) the resulting spectrum of a co-deposition of the dissociation products from an $\mathrm{N}_{2} \mathrm{O}$ plasma with $\mathrm{H}_{2} \mathrm{O}\left(\mathrm{O}: \mathrm{N}_{2} \mathrm{O}: \mathrm{H}_{2} \mathrm{O}=1: 10: 500\right)$ is shown. In curves (b) and (c) the co-deposition spectra have extra features due to added NO; mixing ratios of $\mathrm{O}: \mathrm{NO}: \mathrm{N}_{2} \mathrm{O}: \mathrm{H}_{2} \mathrm{O}=$ $1: 2: 10: 500$ and $1: 10: 10: 500$ are applied, respectively. Curve (d) shows the spectrum resulting from co-deposition of $\mathrm{N}_{2} \mathrm{O}$ dissociation products with $\mathrm{H}_{2} \mathrm{O}$ and ${ }^{18} \mathrm{O}_{2}$ molecules $\left(\mathrm{O}:{ }^{18} \mathrm{O}_{2}: \mathrm{N}_{2} \mathrm{O}: \mathrm{H}_{2} \mathrm{O}=1: 10: 10: 500\right)$.

In this case the oxygen atoms originate from $\mathrm{N}_{2} \mathrm{O}$ dissociation, and the resulting RAIR spectra are very similar to those 


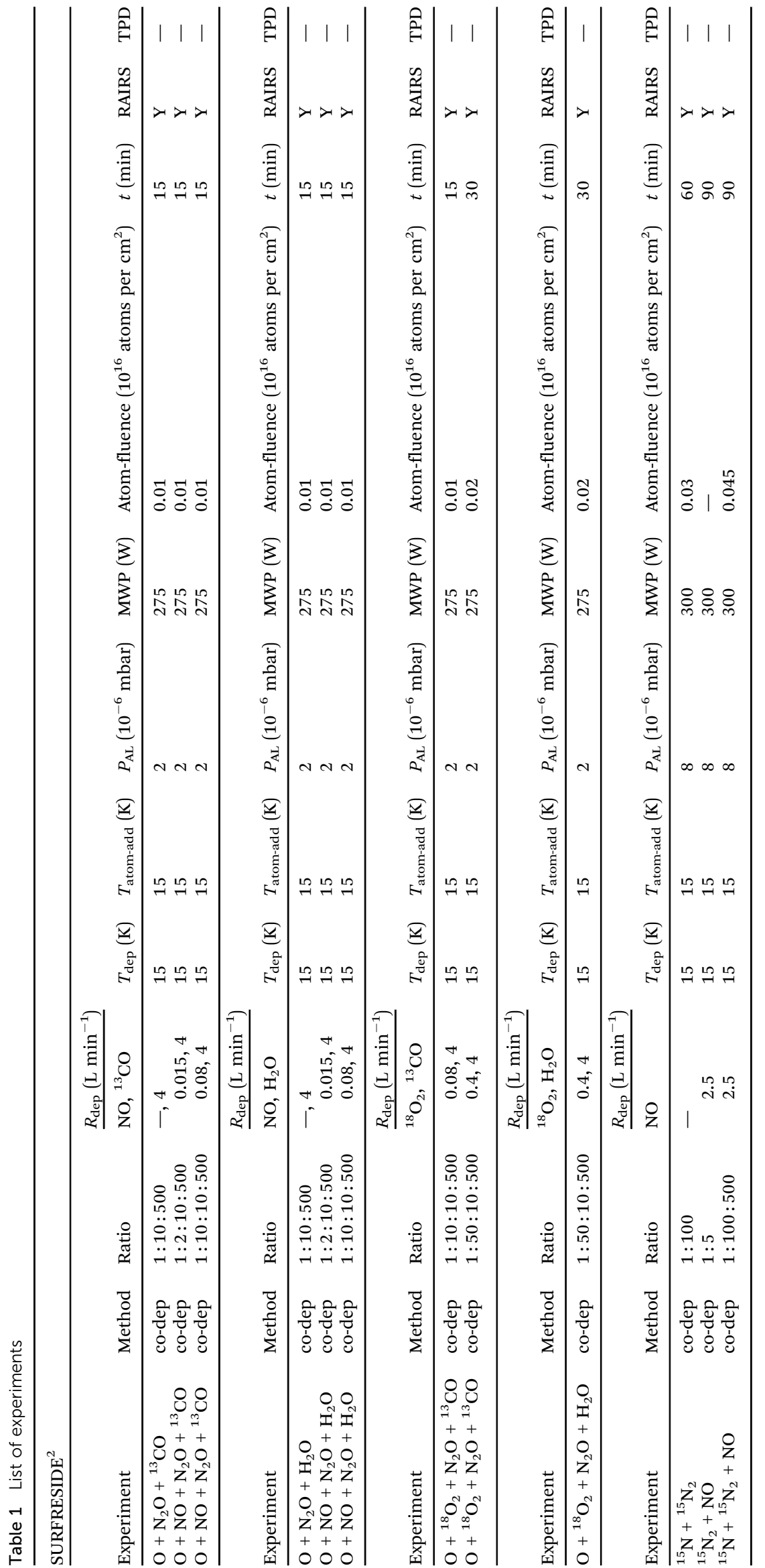




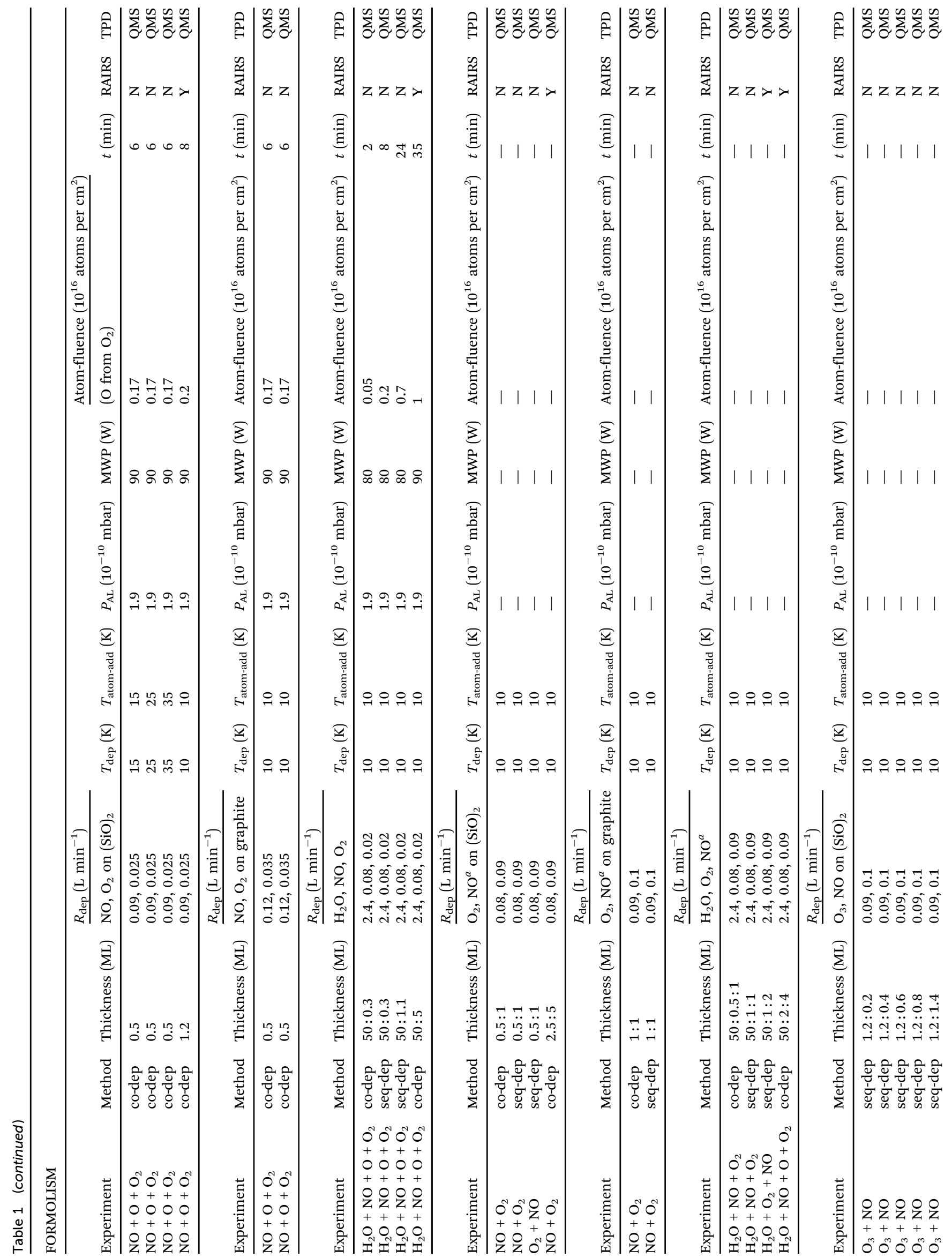




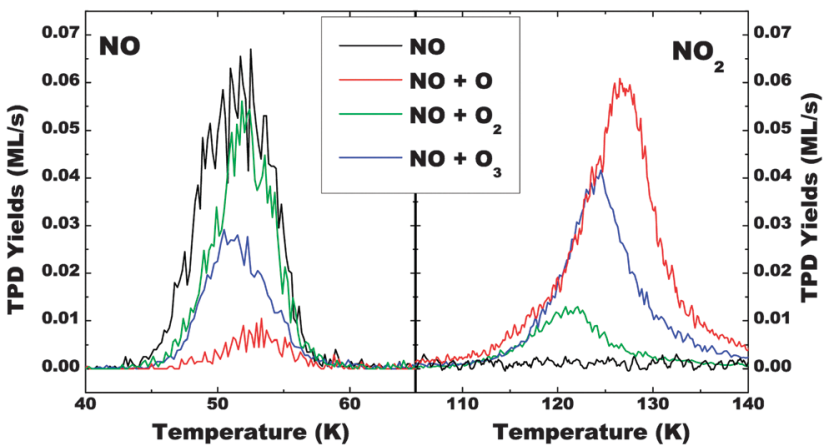

Fig. 1 TPD curves of $\mathrm{NO}$ (mass 30, left-panel) and $\mathrm{NO}_{2}$ (mass 46 , rightpanel) for four different (co)deposition experiments on silicate held at $10 \mathrm{~K}$ : $0.4 \mathrm{ML}$ of $\mathrm{NO}$ (black line), 0.4 ML NO +1.5 ML of O (red line), 0.4 ML NO + $1.5 \mathrm{ML}$ of $\mathrm{O}_{2}$ (green line) and 0.4 ML NO $+1.5 \mathrm{ML}$ of $\mathrm{O}_{3}$ (blue line).

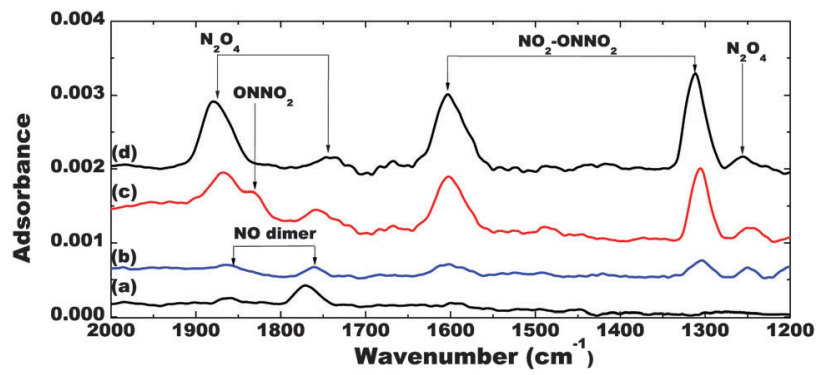

Fig. 2 RAIR spectra obtained after deposition on a silicate sample held at $10 \mathrm{~K}$ of: (a) $1.5 \mathrm{ML}$ of $\mathrm{NO}$; (b) co-deposition of $1.5 \mathrm{ML} \mathrm{NO}+\mathrm{O}$; (c) co-deposition of $3.5 \mathrm{ML}$ of $\mathrm{NO}+\mathrm{O}$; and (d) co-deposition of $3.5 \mathrm{ML}$ of $\mathrm{NO}+\mathrm{O}$, annealing to $86 \mathrm{~K}$ and cooling down to $50 \mathrm{~K}$.

shown in Fig. 2. Moreover, $\mathrm{N}_{2} \mathrm{O}$ (see Table 2) and $\mathrm{H}_{2} \mathrm{O}$ precursor features show up in the spectra. The latter in particular does not allow an unambiguous identification of solid $\mathrm{NO}_{2}$ in curves (b) through (d). The two insets of Fig. 3 show bands due to $\mathrm{NO}$ dimer, $\mathrm{NO}_{2}$ and $\mathrm{ONNO}_{2}$ that only show up when $\mathrm{NO}$ is co-deposited with O-atoms. Furthermore, curve (c) shows peaks of $\mathrm{NO}$ and $\mathrm{N}_{2} \mathrm{O}$ that are also present in the other curves, including the peak in curve (a) at $1861 \mathrm{~cm}^{-1}$ due to cis-(NO) and two more peaks due to $\mathrm{ONNO}_{2}$ at 1834 and $1304 \mathrm{~cm}^{-1}$. The presence of $c i s-(\mathrm{NO})_{2}$ in the ice can be explained by a high NO concentration, while the other two features arise from surface reactions, as will be discussed later. With respect to the previous experiments performed on the silicate sample, here all peak positions are somewhat shifted $\left(5 \mathrm{~cm}^{-1}\right.$ at maximum) because of the polar environment the species are embedded in.

Finally, we have studied the $\mathrm{NO}+\mathrm{O}$ reaction in $\mathrm{a}{ }^{13} \mathrm{CO}$ matrix, i.e., an apolar environment. Fig. 4 shows four more RAIR co-deposition spectra at $15 \mathrm{~K}$. Curve (a) shows $\mathrm{N}_{2} \mathrm{O}$ dissociation products with ${ }^{13} \mathrm{CO}$ molecules $\left(\mathrm{O}: \mathrm{N}_{2} \mathrm{O}:{ }^{13} \mathrm{CO}=\right.$ $1: 10: 500$ ), curves (b) and (c) show $\mathrm{N}_{2} \mathrm{O}$ dissociation products with ${ }^{13} \mathrm{CO}$ and NO molecules (O: NO : $\mathrm{N}_{2} \mathrm{O}:{ }^{13} \mathrm{CO}=1: 2: 10: 500$ and $1: 10: 10: 500$, respectively), and curve (d) shows $\mathrm{N}_{2} \mathrm{O}$ dissociation products with ${ }^{13} \mathrm{CO}$ and ${ }^{18} \mathrm{O}_{2}$ molecules $\left(\mathrm{O}:{ }^{18} \mathrm{O}_{2}: \mathrm{N}_{2} \mathrm{O}:{ }^{13} \mathrm{CO}=\right.$ $1: 50: 10: 500$ ). 


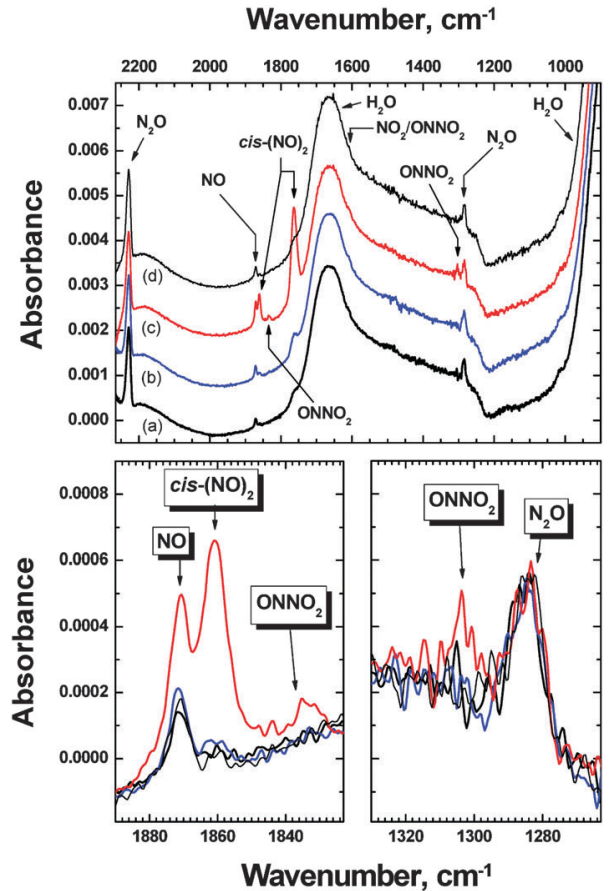

Fig. 3 Top panel: four RAIR spectra of co-depositions at $15 \mathrm{~K}$ of (a) $\mathrm{N}_{2} \mathrm{O}$ plasma dissociation products with $\mathrm{H}_{2} \mathrm{O}$ molecules; (b) and (c) $\mathrm{N}_{2} \mathrm{O}$ plasma dissociation products with $\mathrm{H}_{2} \mathrm{O}$ and $\mathrm{NO}$ molecules (two different mixing ratios, see text); and (d) $\mathrm{N}_{2} \mathrm{O}$ plasma dissociation products with $\mathrm{H}_{2} \mathrm{O}$ and ${ }^{18} \mathrm{O}_{2}$ molecules. The bottom panels show absorption features of solid $\mathrm{ONNO}_{2}\left(\mathrm{~N}_{2} \mathrm{O}_{3}\right)$ in two spectral regions.

In Fig. 4 the $\mathrm{CO}$ signatures (see Table 2) for different isotopologues $\left({ }^{13} \mathrm{CO},{ }^{12} \mathrm{CO},{ }^{13} \mathrm{C}^{17} \mathrm{O}\right.$ and $\left.{ }^{13} \mathrm{C}^{18} \mathrm{O}\right)$, due to impurities present in the ${ }^{13} \mathrm{CO}$ bottle, are clearly visible. In this case, the region of the water bending mode is flat and allows a clear identification of $\mathrm{NO}_{2}$ at $1614 \mathrm{~cm}^{-1}$. The $\mathrm{N}_{2} \mathrm{O}$ and $\mathrm{NO}$ (monomer) spectra are visible in each spectrum. While the $\mathrm{N}_{2} \mathrm{O}$ band positions are almost the same in each spectrum, the band intensities actually depend on the mixing ratio of the deposited species. The NO band is also present in curve (a) although it is not deposited directly in the sample; actually it comes from the $\mathrm{N}_{2} \mathrm{O}$ dissociation as evident in the left-hand panel of Fig. 4 . The $\mathrm{NO}_{2}$ monomer peak (at $1614 \mathrm{~cm}^{-1}$ ) shows the same behaviour as the NO band. It is present in curves (a) and (b), but it gains absorption strength when NO molecules are deposited as shown in curves (b) and (c) (see the central panel of Fig. 4). $\mathrm{O}_{3}$ is formed only when ${ }^{18} \mathrm{O}_{2}$ is co-deposited with $\mathrm{NO}$ and $\mathrm{N}_{2} \mathrm{O}$ dissociation products (see curve $\mathrm{d}$ and the righthand panel).

3.1.1 Dependence on substrate, coverage and temperature. The different substrates (silicate, compact ASW ice, and gold) and the ice composition used do not visibly affect the final products. They are, however, responsible for small shifts of the IR features. Surface coverage only slightly changes the final products of our experiments. In particular, multilayer regimes facilitate dimerization reactions, as we will discuss below in Section 4. In order to investigate any temperature dependence of the $\mathrm{NO}+\mathrm{O}$ reaction, experiments are performed in which the deposition temperature was varied. Fig. 5 shows three NO TPD curves after deposition of $0.5 \mathrm{ML} \mathrm{NO}+1 \mathrm{ML} \mathrm{O}$ on a silicate sample held at $15 \mathrm{~K}$ (dashed curve), $25 \mathrm{~K}$ (solid curve), and $35 \mathrm{~K}$ (dotted curve), respectively. The amount of NO left as a function of substrate temperature (calculated by integrating the area of each NO peak) is plotted in the inset of Fig. 5. Within the experimental error bars, this does not show any substantial temperature dependence. The reaction is already efficient at low temperatures and seems to be essentially barrier free.

Table 2 List of detected features in the RAIR spectra shown in Fig. 2-4, 6 and 7

\begin{tabular}{|c|c|c|c|c|c|c|c|}
\hline \multirow[b]{4}{*}{ Molecule } & \multirow[b]{4}{*}{ Mode } & \multicolumn{6}{|l|}{ Substrate } \\
\hline & & \multicolumn{3}{|l|}{$\underline{(\mathrm{SiO})_{x}}$} & \multirow[t]{2}{*}{$\underline{\mathrm{H}_{2} \mathrm{O} \text { ice }}$} & \multirow[t]{2}{*}{$\underline{\mathrm{CO} \text { ice }}$} & \multirow[t]{2}{*}{ Gold } \\
\hline & & \multicolumn{3}{|l|}{ Experiment } & & & \\
\hline & & $\mathrm{NO}+\mathrm{O}$ & $\mathrm{NO}+\mathrm{O}_{2}\left(\right.$ ref. 6) $\left(\mathrm{cm}^{-1}\right)$ & $\mathrm{NO}+\mathrm{O}_{3}$ & $\mathrm{NO}+\mathrm{N}_{2} \mathrm{O}^{*}\left(\mathrm{~cm}^{-1}\right)$ & $\mathrm{NO}+\mathrm{N}_{2} \mathrm{O}^{*}\left(\mathrm{~cm}^{-1}\right)$ & $\mathrm{NO}+\mathrm{N}\left(\mathrm{cm}^{-1}\right)$ \\
\hline NO & & - & 1897 & - & 1871 & 1876 & - \\
\hline \multirow{2}{*}{ cis-(NO) $)_{2}$} & $\mathrm{~N}-\mathrm{O}$ s-str $\left(\mathrm{a}_{\mathrm{g}}(1)\right)$ & 1861 & 1863 & 1874 & 1861 & 1865 & 1865 \\
\hline & $\mathrm{N}-\mathrm{O}$ a-str $\left(\mathrm{b}_{\mathrm{u}}(5)\right)$ & 1770 & 1776 & 1773 & 1763 & 1770 & 1771 \\
\hline \multirow[t]{2}{*}{$\mathrm{NO}_{2}$} & $\mathrm{~N}-\mathrm{O}$ a-str & 1602 & 1605 & 1612 & 1606 & 1614 & 1606 \\
\hline & $\mathrm{N}-\mathrm{O}$ s-str & $1304-1311$ & 1311 & 1307 & 1304 & 1304 & 1307 \\
\hline \multirow[t]{4}{*}{$\mathrm{ONNO}_{2}$} & $\mathrm{~N}=\mathrm{O}$ str & 1834 & 1834 & 1838 & 1835 & 1840 & 1836 \\
\hline & $\mathrm{N}-\mathrm{O}$ a-str & 1602 & 1605 & 1612 & 1606 & 1614 & 1606 \\
\hline & $\mathrm{N}-\mathrm{O}$ s-str & $1304-1311$ & 1311 & 1307 & 1304 & 1304 & 1307 \\
\hline & $\mathrm{NO}_{2}$ deform & - & - & - & - & - & 774 \\
\hline \multirow[t]{3}{*}{$\mathrm{N}_{2} \mathrm{O}_{4}$} & $\mathrm{~N}=\mathrm{O}$ str & 1878 & 1875 & 1874 & - & - & \\
\hline & $\mathrm{NO}_{2}$ a-str $\left(\mathrm{b}_{3 \mathrm{u}}(11)\right)$ & 1741 & - & - & - & - & \\
\hline & $\mathrm{NO}_{2} \mathrm{~s}-\mathrm{str}\left(\mathrm{b}_{2 \mathrm{u}}(11)\right)$ & 1256 & - & 1255 & - & - & \\
\hline \multirow[t]{2}{*}{$\mathrm{N}_{2} \mathrm{O}$} & NN str & - & - & - & 2254 & 2240 & 2245 \\
\hline & $\mathrm{N}=\mathrm{O}$ str & - & - & - & 1284 & 1288 & \\
\hline${ }^{161616} \mathrm{O}_{3}$ & $\mathrm{O}-\mathrm{O}$ a-str & - & - & 1043 & - & - & - \\
\hline${ }^{181816} \mathrm{O}_{3}$ & $\mathrm{O}-\mathrm{O}$ a-str & - & - & - & - & 974 & - \\
\hline${ }^{12} \mathrm{C}^{16} \mathrm{O}$ & $\mathrm{C}-\mathrm{O}$ a-str & - & - & - & - & 2094 & - \\
\hline${ }^{13} \mathrm{C}^{16} \mathrm{O}$ & $\mathrm{C}-\mathrm{O}$ a-str & - & - & - & - & 2140 & - \\
\hline${ }^{13} \mathrm{C}^{17} \mathrm{O}$ & $\mathrm{C}-\mathrm{O}$ a-str & - & - & - & - & 2020 & - \\
\hline${ }^{13} \mathrm{C}^{18} \mathrm{O}$ & $\mathrm{C}-\mathrm{O}$ a-str & - & - & - & - & 1987 & - \\
\hline
\end{tabular}



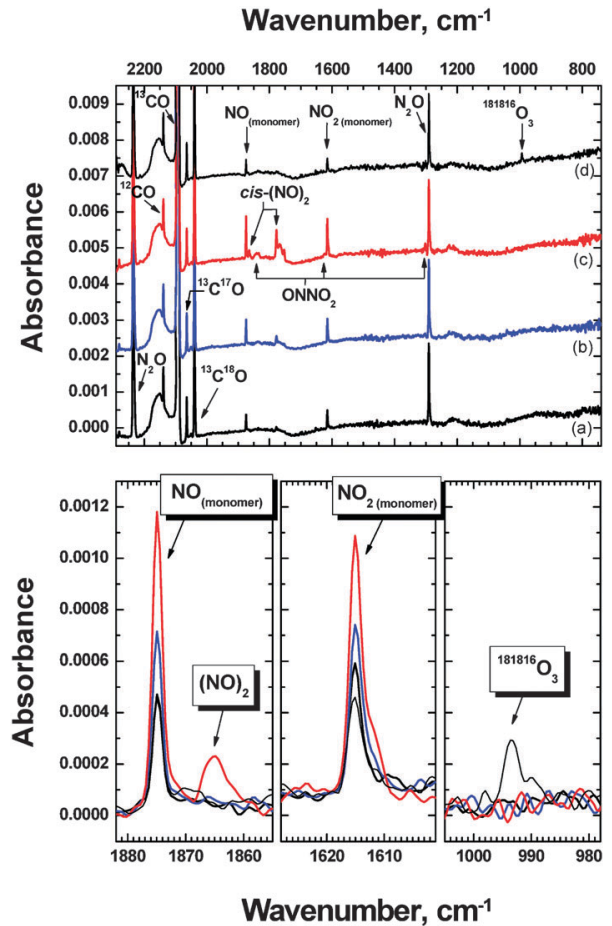

Fig. 4 Top panel: four RAIR co-deposition spectra at $15 \mathrm{~K}$ of: (a) $\mathrm{N}_{2} \mathrm{O}$ plasma dissociation products with ${ }^{13} \mathrm{CO}$ molecules; (b) and (c) $\mathrm{N}_{2} \mathrm{O}$ plasma dissociation products with ${ }^{13} \mathrm{CO}$ and $\mathrm{NO}$ molecules (two different mixing ratios, see text); and (d) $\mathrm{N}_{2} \mathrm{O}$ plasma dissociation products with ${ }^{13} \mathrm{CO}$ and ${ }^{18} \mathrm{O}_{2}$ molecules. The zoom-in panels show absorption features of $\mathrm{NO}$, $\mathrm{NO}_{2}$, and $\mathrm{O}_{3}$ in three different spectral regions.

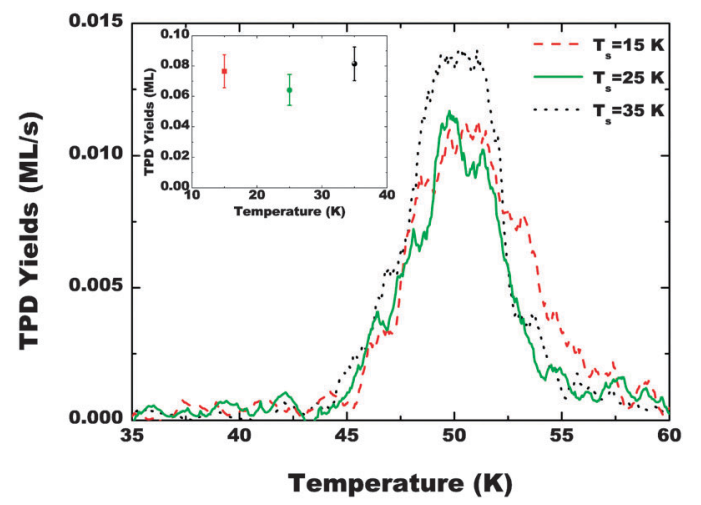

Fig. 5 Three TPD (mass 30) plots of NO after deposition of 0.5 ML NO + $1 \mathrm{MLO}$ at different temperatures: $15 \mathrm{~K}$ (dashed), $25 \mathrm{~K}$ (solid) and $35 \mathrm{~K}$ (dotted). The inset shows the integrated area under the TPD curves.

\section{$3.2 \mathrm{NO}+\mathrm{O}_{2}$}

This reaction has been studied in detail before, ${ }^{6}$ and is discussed here merely for completeness, as this reaction channel is intimately linked to the other two reactions presented here $\mathrm{NO}+\mathrm{O}$ and $\mathrm{NO}+\mathrm{O}_{3}$.

In the $\mathrm{NO}+\mathrm{O}$ experiments the reaction $\mathrm{NO}+\mathrm{O}_{2}$ can take place for two reasons: (i) the oxygen plasma (generated from cracking $\mathrm{O}_{2}$ molecules) is not fully atomic, and about $20-30 \%$ of $\mathrm{O}_{2}$ molecules remain; and (ii) $\mathrm{O}_{2}$ molecules can also form on

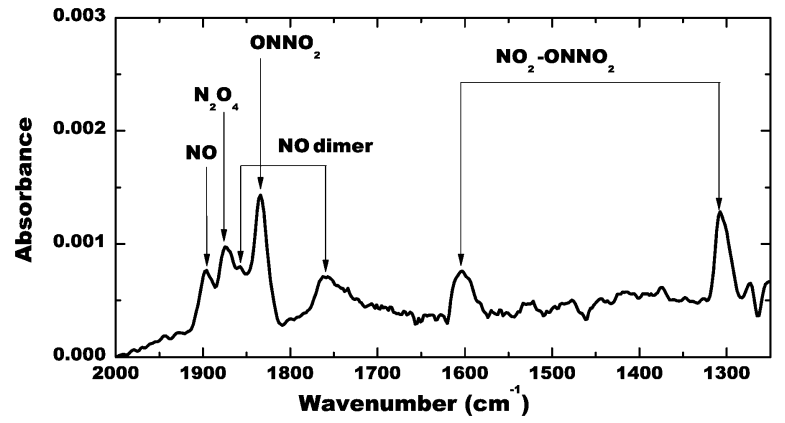

Fig. 6 Adapted from Minissale et al. (2013). ${ }^{6}$ RAIR spectrum of $5 \mathrm{ML} \mathrm{O}_{2}+$ $2.5 \mathrm{ML} \mathrm{NO}$ co-deposited at $10 \mathrm{~K}$ on a silicate surface. Seven features due to $\mathrm{NO},(\mathrm{NO})_{2}, \mathrm{NO}_{2}, \mathrm{ONNO}_{2}$ and $\mathrm{N}_{2} \mathrm{O}_{4}$ are labelled.

the cold surface due to $\mathrm{O}+\mathrm{O}$ recombinations. In the $\mathrm{NO}+\mathrm{O}_{3}$ experiments, $\mathrm{O}_{2}$ molecules are formed through the reaction itself. In Fig. 6 a RAIR spectrum of $5 \mathrm{ML} \mathrm{O}_{2}+2.5 \mathrm{ML}$ NO co-deposited at $10 \mathrm{~K}$ on a silicate surface is shown (taken from ref. 6). The features at 1897 and $1902 \mathrm{~cm}^{-1}$ are assigned to the NO monomer, ${ }^{52}$ and bands at 1863 and $1776 \mathrm{~cm}^{-1}$ are signatures of the NO dimer. ${ }^{52} \mathrm{~N}_{2} \mathrm{O}_{4}$ is represented by a band at $1875 \mathrm{~cm}^{-1} .{ }^{53}$ The broad band at $1311 \mathrm{~cm}^{-1}$ is attributed to the $\nu(\mathrm{N}-\mathrm{O})$ symmetric stretch and the band at $1605 \mathrm{~cm}^{-1}$ to the $\nu(\mathrm{N}-\mathrm{O})$ asymmetric stretch of $\mathrm{NO}_{2}{ }^{54,55}$ The band at $1832 \mathrm{~cm}^{-1}$ originates from the asymmetric stretch of $\mathrm{ONNO}_{2}{ }^{56}$ that most likely also contributes to the bands at $1311 \mathrm{~cm}^{-1}$ and $1605 \mathrm{~cm}^{-1}$. These data are summarized in Table 2.

As described in ref. 6 this illustrates that in $\mathrm{NO}+\mathrm{O}_{2}$ solid state interactions nitrogen dioxide is formed.

\section{$3.3 \mathrm{NO}+\mathrm{O}_{3}$}

In Fig. 7 the results are presented for $1.5 \mathrm{ML}$ pre-deposited $\mathrm{O}_{3}$ being exposed to increasing doses of $\mathrm{NO}$ at $10 \mathrm{~K}$. In this specific case the species are not co-deposited on the surface, as in the case of $\mathrm{NO}+\mathrm{O}$ and $\mathrm{NO}+\mathrm{O}_{2}$, but $\mathrm{O}_{3}$ is first deposited and subsequently bombarded with NO. This procedure does not permit to work with high coverages (more than $2 \mathrm{ML}$ ) because

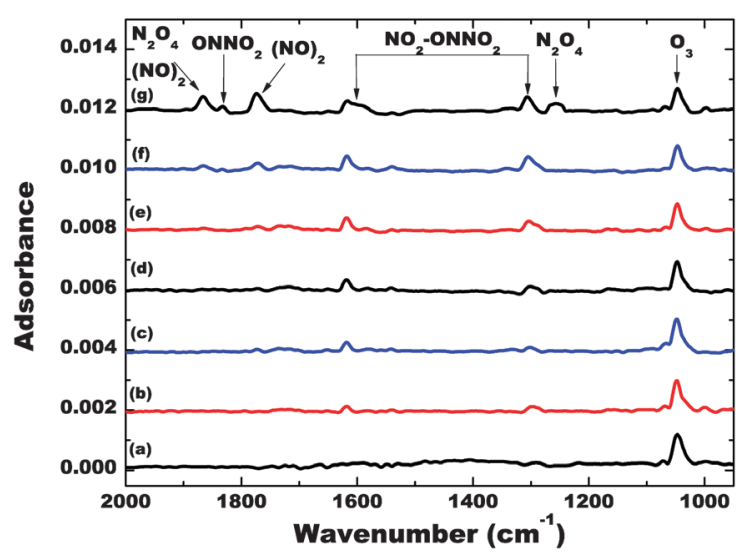

Fig. 7 Seven RAIR spectra after deposition at $10 \mathrm{~K}$ of $1.5 \mathrm{ML} \mathrm{O}_{3}$ with increasing doses of $\mathrm{NO}$ from (a) to (g): $0,0.2,0.4,0.6,0.9,1.8$, and $3.5 \mathrm{ML}$ of $\mathrm{NO}$. 
of layering effects, i.e., for a high NO coverage, the top NO layers will not react with $\mathrm{O}_{3}$ molecules since ozone is shielded by the underlying NO molecules. This effect is partially visible in Fig. 7, where it is possible to follow the (dis)appearance of spectral features as a function of NO coverage. The spectrum in panel (a) is obtained after deposition of $1.5 \mathrm{ML} \mathrm{O}_{3}\left(1043 \mathrm{~cm}^{-1}\right.$, see Table 2). The NO coverage increases from 0.2 ML (curve b) to 3.5 ML (curve $\mathrm{g}$ ), while the intensity of the $\mathrm{O}_{3}$ band slowly decreases, and that of the nitrogen oxide bands $\left(\mathrm{NO}_{2}, \mathrm{ONNO}_{2}\right.$, $\mathrm{N}_{2} \mathrm{O}_{4}$ and $(\mathrm{NO})_{2}$ ) increases.

In line with the spectra recorded for $\mathrm{NO}+\mathrm{O}$ and $\mathrm{NO}+\mathrm{O}_{2}$ we assign the bands at 1874 and $1773 \mathrm{~cm}^{-1}$ to the NO dimer. ${ }^{52}$ $\mathrm{N}_{2} \mathrm{O}_{4}$ is found at $1874 \mathrm{~cm}^{-1} \cdot{ }^{53}$ The broad band at $1307 \mathrm{~cm}^{-1}$ is attributed to the $\nu(\mathrm{N}-\mathrm{O})$ symmetric stretch of $\mathrm{NO}_{2}$ (or $\mathrm{ONNO}_{2}$ ) and the band at $1612 \mathrm{~cm}^{-1}$ to the $\nu(\mathrm{N}-\mathrm{O})$ asymmetric stretch of $\mathrm{NO}_{2}$ (or $\mathrm{ONNO}_{2}$ ). ${ }^{54,55}$ The band at $1838 \mathrm{~cm}^{-1}$ is due to the asymmetric stretch of $\mathrm{ONNO}_{2} \cdot{ }^{56}$

Similar experiments have been conducted on a surface of nonporous (compact) amorphous solid water ice and no evident differences - except for small band shifts - have been found.

\section{$3.4 \mathrm{NO}+\mathrm{N}$}

This reaction has been studied before, ${ }^{42}$ and is presented here for completeness, to show the full $\mathrm{N}-\mathrm{O}$ solid state chemical network.

Fig. 8 shows three RAIR spectra recorded at a gold sample held at $15 \mathrm{~K}$ using $\mathrm{N}_{2}$ dissociation. In curve (a) the resulting

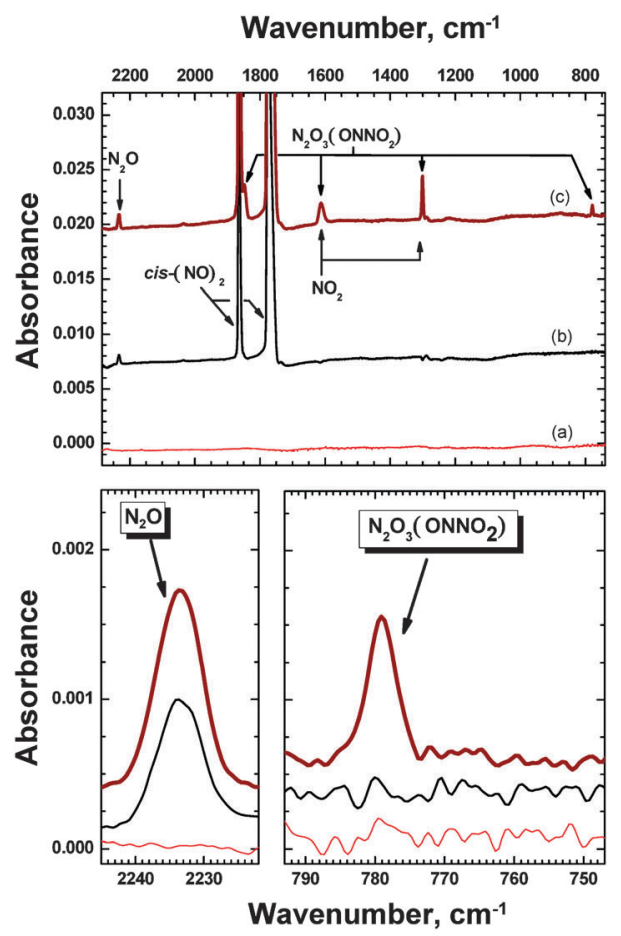

Fig. 8 In the top image three RAIR spectra are shown: (a) co-deposition of $\mathrm{N}$ atoms at $15 \mathrm{~K}\left(\mathrm{~N}: \mathrm{N}_{2}=1: 100\right)$; (b) co-deposition of $\mathrm{N}_{2}$ (plasma "off") with NO molecules $\left(\mathrm{N}_{2}: \mathrm{NO}=100: 500\right)$ at $15 \mathrm{~K}$; and (c) co-deposition of $\mathrm{N}$ atoms with $\mathrm{NO}$ molecules $\left(\mathrm{N}: \mathrm{N}_{2}: \mathrm{NO}=1: 100: 500\right)$ at $15 \mathrm{~K}$. On the bottom picture regions of the spectra are magnified to indicate observed formation of dinitrogen trioxide $\left(\mathrm{ONNO}_{2}\right)$ on the right panel and of $\mathrm{N}_{2} \mathrm{O}$ on the left panel. spectrum of co-deposition of $\mathrm{N}$ atoms at $15 \mathrm{~K}$ is shown $\left(\mathrm{N}: \mathrm{N}_{2}=\right.$ $1: 100$ ); curve (b) shows co-deposition of $\mathrm{N}_{2}$ (dissociation "off") with NO molecules $\left(\mathrm{N}_{2}: \mathrm{NO}=100: 500\right)$ at $15 \mathrm{~K}$, while curve (c) results from co-deposition of $\mathrm{N}$ atoms with $\mathrm{NO}$ molecules $\left(\mathrm{N}: \mathrm{N}_{2}: \mathrm{NO}=1: 100: 500\right)$ at $15 \mathrm{~K}$.

In curve (a) we cannot identify any spectral features while curves (b) and (c) present features due to added NO, i.e., the two cis-(NO) $)_{2}$ bands at 1865 and $1771 \mathrm{~cm}^{-1}$. In curve (c) we can also see two bands due to $\mathrm{NO}_{2}$ and $\mathrm{ONNO}_{2}$ at 1606 and $1307 \mathrm{~cm}^{-1}$, respectively. Two more bands at 1836 and $774 \mathrm{~cm}^{-1}$ are assigned to $\mathrm{ONNO}_{2}$. Furthermore, curves (b) and (c) show a band due to $\mathrm{N}_{2} \mathrm{O}$ at $2245 \mathrm{~cm}^{-1}$; the presence of $\mathrm{N}_{2} \mathrm{O}$ is likely the result of contamination in the $\mathrm{NO}$ gas bottle. The presence of cis-(NO) $)_{2}$ can be explained by a high NO concentration, while the $\mathrm{NO}_{2}$ and $\mathrm{ONNO}_{2}$ features arise from surface reactions, as will be discussed later.

\section{Discussion}

\subsection{The solid surface reaction network}

All experiments presented in Section 3 have in common that solid NO reacts with all the allotropes of oxygen $\left(\mathrm{O}, \mathrm{O}_{2}\right.$ and $\left.\mathrm{O}_{3}\right)$ and $\mathrm{N}$ atoms lead to a reduction of the NO abundance and the formation of new molecular species. The formation of these molecules - as concluded from the presented low temperature RAIR spectra - is explained by a set of partially coupled reactions. $\mathrm{NO}_{2}$ is formed through reactions (1) to (3):

$$
\begin{gathered}
\mathrm{NO}+\mathrm{O} \rightarrow \mathrm{NO}_{2} \\
\mathrm{NO}+\mathrm{O}_{2} \rightarrow \mathrm{NO}_{3} \stackrel{+\mathrm{NO}}{\longrightarrow} 2 \mathrm{NO}_{2} \\
\mathrm{NO}+\mathrm{O}_{3} \rightarrow \mathrm{NO}_{2}+\mathrm{O}_{2} .
\end{gathered}
$$

Reactions (4) to (6) result in the formation of more complex nitrogen oxides without actually involving any oxygen allotrope:

$$
\begin{gathered}
\mathrm{NO}+\mathrm{NO} \rightarrow(\mathrm{NO})_{2} \\
\mathrm{NO}+\mathrm{NO}_{2} \rightarrow \mathrm{ONNO}_{2} \\
\mathrm{NO}_{2}+\mathrm{NO}_{2} \rightarrow\left(\mathrm{NO}_{2}\right)_{2} .
\end{gathered}
$$

Two recombination reactions (7) and (8) lead to the formation of oxygen allotropes: ${ }^{57,58}$

$$
\begin{aligned}
& \mathrm{O}+\mathrm{O} \rightarrow \mathrm{O}_{2} \\
& \mathrm{O}+\mathrm{O}_{2} \rightarrow \mathrm{O}_{3}
\end{aligned}
$$

showing that the reactions $\mathrm{NO}+\mathrm{O}, \mathrm{NO}+\mathrm{O}_{2}$ and $\mathrm{NO}+\mathrm{O}_{3}$ cannot be studied independently of each other and cross-channels have to be taken into account. Moreover another reaction that allows the re-formation of NO should be considered:

$$
\mathrm{NO}_{2}+\mathrm{O} \rightarrow \mathrm{NO}+\mathrm{O}_{2}
$$

Actually, as shown in the Results section, in $\mathrm{NO}+\mathrm{O}$ experiments almost all NO molecules are consumed suggesting that NO-consumption reactions (mainly reaction (1)) are quicker 


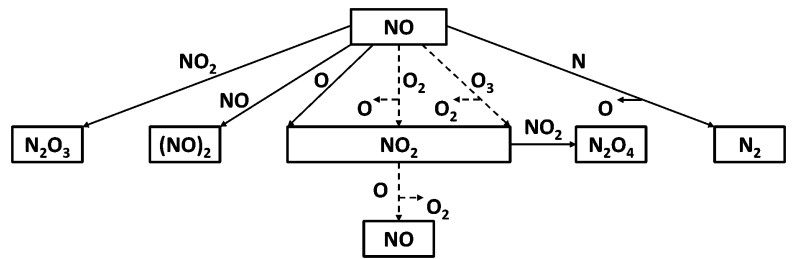

Fig. 9 Schematic representation of the reaction scheme, involving $\mathrm{NO}+$ $\mathrm{O} / \mathrm{O}_{2} / \mathrm{O}_{3}$ reactions. Solid lines are the reactions with no barrier and dashed lines are the reactions with a small barrier.

than the NO-formation reaction (reaction (9)) (in other words $k_{\mathrm{NO}+\mathrm{O}} \gg k_{\mathrm{NO}_{2}+\mathrm{O}}$ ). For this reason we neglect reaction (9) in the present work and refer to Part II for more details.

Finally, the last reaction that we have to consider is:

$$
\mathrm{NO}+\mathrm{N} \rightarrow \mathrm{N}_{2}+\mathrm{O}
$$

This reaction consumes NO and is closely linked to the other reactions. Actually by producing $\mathrm{O}$-atoms, it is able to induce the formation of other molecules (the main products are $\mathrm{NO}_{2}$ and $\mathrm{ONNO}_{2}$ ) via reactions (1)-(9).

Fig. 9 shows a streamlined scheme of all possible surface reactions of $\mathrm{NO}$ and $\mathrm{NO}_{2}$ molecules with $\mathrm{O}, \mathrm{O}_{2}, \mathrm{O}_{3}$, and $\mathrm{N}$. The hydrogenation of NO has been already studied in ref. 25-27. The reaction of $\mathrm{NO}$ with $\mathrm{N}$ atoms has been described in ref. 42 . The channel $\mathrm{NO}+\mathrm{H}$ is not shown here, as NO oxygenation is the main topic of this paper. In order to characterize the full reaction network of oxidation of $\mathrm{NO}$, we start from the simplest and most independent pathway: $\mathrm{NO}+\mathrm{O}_{2}$. When $\mathrm{NO}$ arrives at the surface, it reacts either through reaction (2) or (4). In ref. 6 it was shown that the two reactions are mutually exclusive. $\mathrm{NO}_{3}$ is the first intermediate in the reaction $\mathrm{NO}+\mathrm{O}_{2}$ (reaction (2)), but $\mathrm{NO}_{3}$ is not observed in the FT-RAIR spectra. This is because $\mathrm{NO}_{3}$ is a highly unstable molecule; if it does not react with $\mathrm{NO}$ to form $\mathrm{NO}_{2}$, it will dissociate very fast yielding $\mathrm{NO}+\mathrm{O}_{2}$. Indeed, reactive intermediates in solid surface reaction schemes are generally hard to observe. Reaction (2) takes place during the deposition phase mainly following an Eley-Rideal (ER) mechanism. NO dimerisation together with the saturation of the ER mechanism are the limiting factors for reaction (2) to occur. Once $\mathrm{NO}_{2}$ is formed, it can react with $\mathrm{NO}$ or $\mathrm{NO}_{2}$ to form $\mathrm{ONNO}_{2}$ or $\mathrm{N}_{2} \mathrm{O}_{4}$ (reactions (5) and (6)).

The reaction $\mathrm{NO}+\mathrm{O}_{3}$ is obviously strongly connected to reaction $\mathrm{NO}+\mathrm{O}_{2}$. In fact, when $\mathrm{NO}$ and $\mathrm{O}_{3}$ form $\mathrm{NO}_{2}$ and $\mathrm{O}_{2}$ through reaction (3), solid $\mathrm{O}_{2}$ contributes to $\mathrm{NO}_{2}$ formation via reaction (2). As it is not possible to co-deposit a pure beam of $\mathrm{O}_{3}$ - reaction (8) is far from complete - NO has been deposited on top of pre-deposited $\mathrm{O}_{3}$. Two different phases can be distinguished. Initially when the NO coverage is low $(<1 \mathrm{ML})$, $\mathrm{O}_{3}$ adsorbed on the surface is consumed in Eley-Rideal like reactions by NO depletion from the gas phase. When $\mathrm{NO}_{2}$ and $\mathrm{O}_{2}$ surface densities start to increase, the $\mathrm{NO}+\mathrm{O}_{3}$ reaction probability decreases, and instead, reactions (2) and (5) gain in efficiency. At that stage it is unlikely that $\mathrm{NO}_{2}$ forms following reaction (3).

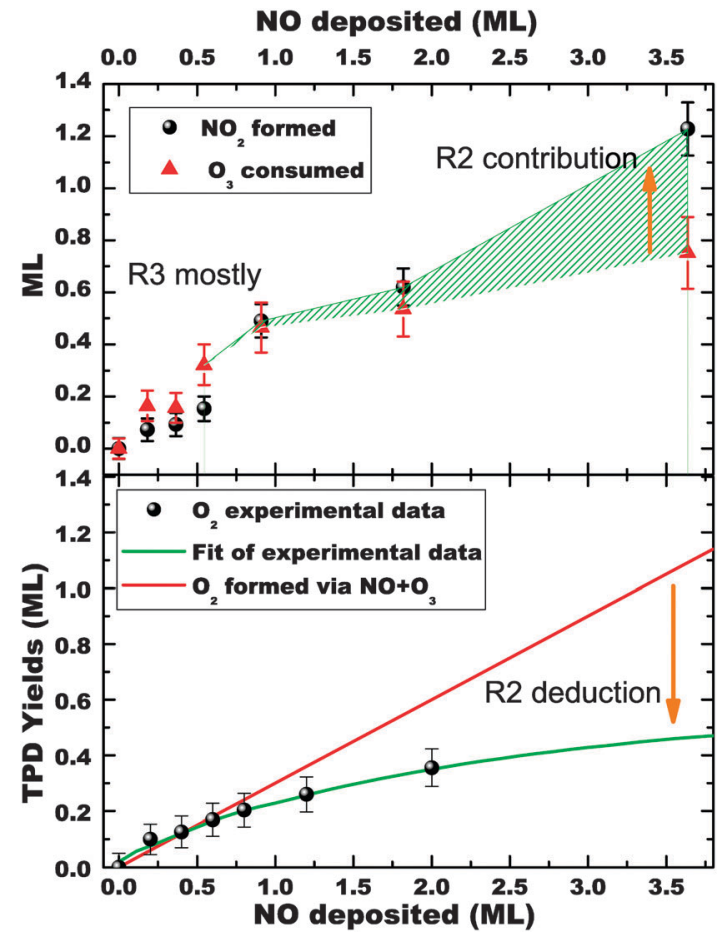

Fig. 10 Top panel: integrated area of $\mathrm{NO}_{2}$ (black circles) and consumed $\mathrm{O}_{3}$ (red triangles) peaks as shown in Fig. 7. Red triangles are obtained by subtracting the integrated area of $\mathrm{O}_{3}(\mathrm{NO}=x)$ from $\mathrm{O}_{3}(\mathrm{NO}=0)$. The green pinstriped zone indicates the zone where reaction (2) starts to be efficient. Bottom panel: integrated area of $\mathrm{O}_{2}$ TPD curves (black circles) as a function of deposited NO, and corresponding fit (green solid line); the red solid line shows the theoretical amount of $\mathrm{O}_{2}$ formed via the $\mathrm{NO}+\mathrm{O}_{3}$ reaction.

The top panel of Fig. 10 shows the integrated area of the $\mathrm{NO}_{2}$ and $\mathrm{O}_{3}$ features $\dagger$ as shown in Fig. 7. The lower panel of Fig. 9 shows the integrated area of the TPD curves of the infrared inactive $\mathrm{O}_{2}$ as obtained through a similar set of experiments that are not shown in the Results section. For a NO coverage lower than $1 \mathrm{ML}$, the consumption of $\mathrm{O}_{3}$ and the formation of $\mathrm{NO}_{2}$ behave linearly. The formation of $\mathrm{O}_{2}$ follows a similar trend. Gradually (for NO coverages thicker than $1 \mathrm{ML}$ ), the formed $\mathrm{O}_{2}$ (experimental points) starts to separate from the linear regime. This is expected as the $\mathrm{O}_{2}$ reacts with NO through reaction (2) and $\mathrm{O}_{2}$ cannot be formed anymore, since the NO molecules cannot react efficiently with the underlying $\mathrm{O}_{3}$. Both effects decrease the $\mathrm{O}_{2}$ abundance. Also $\mathrm{O}_{3}$ is just partially consumed at this point. This is shown in Fig. 10 by the saturation of $\mathrm{O}_{3}$. After a similar initial saturation, $\mathrm{NO}_{2}$ concentration continues to increase (NO coverage $>2 \mathrm{ML}$ ) through reaction (2) as shown in the pinstriped zone in Fig. 10.

Finally, the NO $+\mathrm{O}$ reaction is discussed. The choice of generating $\mathrm{O}$ atoms by dissociating $\mathrm{N}_{2} \mathrm{O}$ or $\mathrm{O}_{2}$ has the potential to change the reaction pathways in our experiments. When $\mathrm{O}$ atoms are produced through $\mathrm{N}_{2} \mathrm{O}$ dissociation, the amount of $\mathrm{O}_{2}$ landing on the ice is negligible and therefore only reactions (1), (4),

$\dagger$ The $\mathrm{O}_{3}$ plotted in Fig. 7 is the $\mathrm{O}_{3}$ consumed by the reactions with respect to the initial amount of $\mathrm{O}_{3}$ (i.e., $\mathrm{O}_{3}(\mathrm{NO}=0)-\mathrm{O}_{3}(\mathrm{NO}=x)$ ). 
and (7) are in competition. In ref. 58 it was shown that reaction (7) is barrierless or has a very small barrier. Also reaction (4) that leads to the dimerization of NO is barrierless. This is confirmed by the RAIR spectra of pure NO deposited at low temperature, where only the $(\mathrm{NO})_{2}$ features are detected (see Fig. 2). To avoid NO dimerization, NO has been deposited in a matrix of other species (e.g., $\mathrm{NO}: \mathrm{H}_{2} \mathrm{O}$ and NO:CO, as shown in Fig. 3 and 4). In this case, the NO monomer becomes visible in the RAIR spectra, starting from polar and apolar ices, respectively. These experiments confirm the fast formation of $\mathrm{NO}_{2}$ at low temperature also in different matrix environments.

When O-atoms are produced through $\mathrm{O}_{2}$ dissociation, $\mathrm{O}_{2}$ molecules can still reach the surface. This also means that $\mathrm{O}_{2}$ can react with oxygen atoms to form $\mathrm{O}_{3}$ (reaction (8)), specifically when the species are co-deposited. So the formation of $\mathrm{NO}_{2}$ can occur via reactions (1)-(3). In the case that $\mathrm{O}+\mathrm{O}_{2}$ impact on already surface accreted NO molecules, reaction (3) is less probable $\neq$ and the possible pathways are limited to reactions (1) and (2). This is the case in Fig. 1 (red line) where almost all the $\mathrm{NO}$ is converted into $\mathrm{NO}_{2}$ and only a small part (about $8 \%$ ) of NO molecules does not react. The incomplete conversion of $\mathrm{NO}$ into $\mathrm{NO}_{2}$ is most likely not due to an activation barrier of reaction (1). It can be explained by a low penetration depth of $\mathrm{O}$ atoms into the NO ice, together with a small mismatch between the areas covered by the two beams (NO and O) in FORMOLISM, as well as recombination reactions $\mathrm{O}+\mathrm{O}\left(\mathrm{O}+\mathrm{O}_{2}\right)$ that lead to the formation of $\mathrm{O}_{2}\left(\mathrm{O}_{3}\right)$. As $\mathrm{O}_{2}$ (as well as newly formed $\mathrm{O}_{3}$ molecules) is less reactive than $\mathrm{O}$ in reactions with $\mathrm{NO}$, this can further slow down the destruction of $\mathrm{NO}$ and parallel formation of $\mathrm{NO}_{2}$.

Different physical conditions have been used to constrain the reaction mechanisms. Generally, this has not resulted in pronounced dependencies as already discussed in 3.1.1 for the surface temperature and coverage. In the case of the multilayer regime experiments, the dimerization channels (reactions (4)-(6)) seem to be more efficient with respect to the sub-monolayer case, likely because of a higher density of reactants. Also the different substrates do not weight on the results strongly, mainly causing small spectral shifts as listed in Table 2 .

\subsection{Physical chemical processes}

From a physical-chemical point of view, all our results lead to the same conclusion: $\mathrm{NO}$ is very reactive with $\mathrm{N}$ and $\mathrm{O}_{x}$ and the reaction products are nitrogen oxides. These results can be explained by having a look at the standard enthalpy of the molecules at play. Table 3 lists the standard enthalpy values $(\Delta H)$ for stable $\mathrm{N}_{x} \mathrm{O}_{y}$ molecules, with $x$ between 0 and 2 and $y$ between 0 and 4 . The values are included between 0 and $472 \mathrm{~kJ} \mathrm{~mol}^{-1}$. If we do not consider the most stable $\left(\mathrm{N}_{2}\right.$ and $\left.\mathrm{O}_{2}\right)$ and unstable ( $\mathrm{N}$ and $\mathrm{O}$ ) species, we notice that the enthalpy difference is $\approx 160 \mathrm{~kJ} \mathrm{~mol}^{-1}$. This fact suggests that all molecules can be easily transformed into each other in the presence

‡ Actually $\mathrm{O}_{3}$ formation is a secondary process. $\mathrm{O}+\mathrm{O}_{2}$ reaction is almost prevented because both $\mathrm{O}$ and $\mathrm{O}_{2}$ can react with NO instead of reacting with each other to form $\mathrm{O}_{3}$.
Table 3 List of standard enthalpy - expressed in $\mathrm{kJ} \mathrm{mol}^{-1}$ and $\mathrm{eV}$ - for stable $\mathrm{N}_{x} \mathrm{O}_{y}$ molecules

\begin{tabular}{|c|c|c|c|}
\hline \multirow{2}{*}{$\frac{\text { Atom } / \text { molecule }}{\text { Name (molecular formula) }}$} & \multicolumn{3}{|l|}{$\Delta H^{a}$} \\
\hline & uma & $\mathrm{kJ} \mathrm{mol}^{-1}$ & $\mathrm{eV}$ \\
\hline Nitrogen (N) & 14 & 472.62 & 4.89 \\
\hline Oxygen (O) & 16 & 249.18 & 2.58 \\
\hline Molecular nitrogen $\left(\mathrm{N}_{2}\right)$ & 28 & 0 & 0 \\
\hline Nitric oxide (NO) & 30 & 90.29 & 0.94 \\
\hline Dioxygen $\left(\mathrm{O}_{2}\right)$ & 32 & 0 & 0 \\
\hline Nitrous oxide $\left(\mathrm{N}_{2} \mathrm{O}\right)$ & 44 & 82 & 0.85 \\
\hline Nitrogen dioxide $\left(\mathrm{NO}_{2}\right)$ & 46 & 33.1 & 0.34 \\
\hline Ozone $\left(\mathrm{O}_{3}\right)$ & 48 & 142.67 & 1.48 \\
\hline $\begin{array}{l}\text { Nitric oxide-dimer } \\
\left(\mathrm{N}_{2} \mathrm{O}_{2} \text { or }(\mathrm{NO})_{2}\right)\end{array}$ & 60 & $170.33^{b}$ & $1.76^{b}$ \\
\hline $\begin{array}{l}\text { Dinitrogen trioxide } \\
\left(\mathrm{N}_{2} \mathrm{O}_{3} \text { or } \mathrm{ONNO}_{2}\right)\end{array}$ & 78 & 82.8 & 0.86 \\
\hline $\begin{array}{l}\text { Dinitrogen tetroxide } \\
\mathrm{N}_{2} \mathrm{O}_{4}\end{array}$ & 96 & 9 & 0.09 \\
\hline
\end{tabular}

of $\mathrm{O}$ and $\mathrm{N}$ atoms, taking into account the activation barrier for every single case. Actually Fig. 11 is a schematic 3D representation of the N/O network, where we consider just the stable molecules. Their stability and formation enthalpies are represented vertically (the smaller the enthalpy the more stable the molecules). We have drawn the different reactions identified experimentally in this work. Presented in this way, $(\mathrm{NO})_{2}$ formation seems to be not very likely (from an energetic point of view) while $\mathrm{NO}_{2}, \mathrm{ONNO}_{2}$, and $\mathrm{N}_{2} \mathrm{O}_{4}$ are clearly the more stable molecules in the solid state processes involving nitrogen and oxygen.

Since the difference between enthalpies of these three molecules is very small $\left(<73 \mathrm{~kJ} \mathrm{~mol}^{-1}\right)$ and reactions (1), (5),

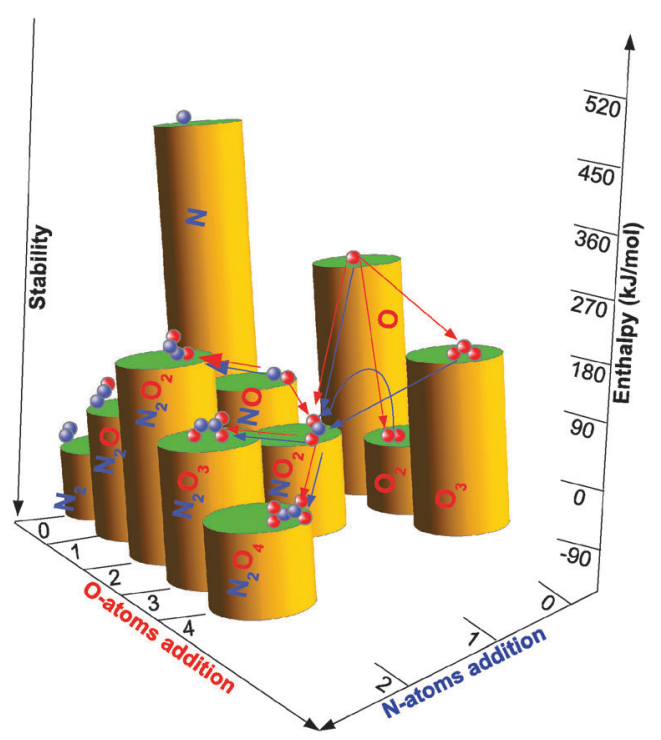

Fig. 11 Schematic 3D representation of the N/O network. The two axes in the horizontal plane represent $\mathrm{O}$-atom and $\mathrm{N}$-atom additions. Standard enthalpies grow along the vertical axis. The arrows represent the reaction studied in this work. In particular red and blue arrows represent $\mathrm{O}$-atom and $\mathrm{N}$-atom addition, respectively. The solid arrows represent barrierless reactions, while curved ones indicate reactions with an activation barrier. 
(6) and (10) have no activation barrier, the ratio between $\mathrm{N}_{x} \mathrm{O}_{y}$ species, in our experiments, can be explained through surface (or volume) densities of $\mathrm{NO}$ and $\mathrm{O}$ atoms ( $\mathrm{N}$ atoms). We can consider three different cases:

(1) No O atoms ( $\mathrm{N}$ atoms), only NO molecules present. In this case just dimers of nitric oxide, $(\mathrm{NO})_{2}$, can form. The abundances are $(\mathrm{NO})_{2}>\mathrm{NO} \gg \mathrm{NO}_{2}=\mathrm{ONNO}_{2}=\mathrm{N}_{2} \mathrm{O}_{4}=0$.

(2) Sub-monolayer regime (low $\mathrm{NO}$ and $\mathrm{O} / \mathrm{N}$ densities, with $\mathrm{O} \geq \mathrm{NO}$ or $\mathrm{N} \geq \mathrm{NO}$ ), with or without a water (or $\mathrm{CO}$ ) matrix. Small amounts of $\mathrm{NO}_{2}$ can be formed and therefore the dimerization processes (reactions (5) and (6)) are limited. (NO) $)_{2}$ reacts with O-atoms to form $\mathrm{NO}_{2}$. In this case $\mathrm{NO}_{2}>\mathrm{ONNO}_{2}>\mathrm{N}_{2} \mathrm{O}_{4} \gg$ $\mathrm{NO} \approx(\mathrm{NO})_{2} \approx 0$.

(3) Multilayer regime ( $\mathrm{O} \geq \mathrm{NO}$ ). $\mathrm{NO}_{2}$ can be formed very efficiently, it can react with $\mathrm{NO}$ or another $\mathrm{NO}_{2}$. In this case $0 \approx \mathrm{NO} \approx(\mathrm{NO})_{2} \ll \mathrm{NO}_{2}<\mathrm{ONNO}_{2}, \mathrm{~N}_{2} \mathrm{O}_{4}$. The $\mathrm{ONNO}_{2} / \mathrm{N}_{2} \mathrm{O}_{4}$ ratio depends on the surrounding environment:

(a) With matrix - the presence of water or CO surrounding helps the diffusion of the lightest molecules (NO) and prevents $\mathrm{NO}_{2}$ molecules from meeting and reacting. Actually the formation of $\mathrm{ONNO}_{2}$ is more likely with respect to $\mathrm{N}_{2} \mathrm{O}_{4}$. In this case $\mathrm{ONNO}_{2}>\mathrm{N}_{2} \mathrm{O}_{4}$.

(b) Without matrix - newly formed $\mathrm{NO}_{2}$ molecules can react both with $\mathrm{NO}_{2}$ and NO. In this case $\mathrm{ONNO}_{2} \approx \mathrm{N}_{2} \mathrm{O}_{4}$.

Clearly from an astrochemical point of view the final products are dependent not only on their stability but also on the speed of the reaction and above all on interstellar abundances of reactants, as discussed in Part II.

\section{Conclusions}

In the present work the surface consumption of NO has been studied via solid surface reactions with $\mathrm{O} / \mathrm{O}_{2} / \mathrm{O}_{3} / \mathrm{N}$ at low temperatures and under UHV conditions. From this study we draw the following conclusions:

- Oxygenation and nitrogenation routes $\left(\mathrm{NO}+\mathrm{O} / \mathrm{O}_{2} / \mathrm{O}_{3} / \mathrm{N}\right)$ have comparable effects on $\mathrm{NO}$ ices. The reactions $\mathrm{NO}+\mathrm{O} / \mathrm{N}$ are barrierless, while $\mathrm{NO}+\mathrm{O}_{2} / \mathrm{O}_{3}$ present a small barrier. Actually $\mathrm{NO}+\mathrm{O} / \mathrm{N}$ routes are the most efficient in consuming $\mathrm{NO}$ and, by considering interstellar abundances $\left(\mathrm{O} \approx \mathrm{N}>\mathrm{O}_{2}>\mathrm{O}_{3}\right)$, they are also the most probable surface reactions on icy dust grains. From an astrophysical point of view, the difference between observed and theoretical abundance of NO is probably due to lacking destruction (i.e., consumption) routes in the astrochemical models.

- $\mathrm{NO}_{2}$ is easily formed via $\mathrm{NO}+\mathrm{O} / \mathrm{O}_{2} / \mathrm{O}_{3} / \mathrm{N}$ solid surface reactions. In its turn $\mathrm{NO}_{2}$ is very efficient to react with $\mathrm{NO}$ to form $\mathrm{ONNO}_{2}$ or to dimerize with other $\mathrm{NO}_{2}$ to form $\mathrm{N}_{2} \mathrm{O}_{4}$. The non-detection of $\mathrm{NO}_{2}$ (and of course of $\mathrm{ONNO}_{2}$ ) in the ISM may have a clear chemical reason following an efficient destruction mechanism, such as surface $\mathrm{NO}_{2}+\mathrm{H} / \mathrm{O} / \mathrm{N}$ reactions (discussed in Part II). This can lead to abundances too low to be observable with the available sensitivity and spatial resolution of the present telescopes. Clearly, from an astrophysical point of view, due to the small abundance of NO, the solid state formation of $\mathrm{ONNO}_{2}$ is less probable with respect to $\mathrm{NO}_{2}$.
- This experimental work, together with Part II, contributes to a better understanding of $\mathrm{H} / \mathrm{N} / \mathrm{O}$ chemistry in the ISM and gives an almost complete solid state network of the formation and evolution of nitrogen oxides.

The LERMA-LAMAp team acknowledges the support of the national PCMI programme founded by CNRS. M.M. and G.F. acknowledge LASSIE, a European FP7 ITN Community's Seventh Framework Programme under Grant Agreement No. 238258. Support for S.I. from the Niels Stensen Fellowship and the Marie Curie Fellowship (FP7-PEOPLE-2011-IOF-300957) is gratefully acknowledged. The work in Leiden is supported by NOVA and NWO.

\section{References}

1 E. Jenkins, Astrophys. J., 2009, 700, 1299-1348.

2 E. A. Bergin and M. Tafalla, Annu. Rev. Astron. Astrophys., 2007, 45, 339-396.

3 K. Hiraoka and T. Sato, Radiat. Phys. Chem., 2001, 60, 389.

4 E. Matar, E. Congiu, F. Dulieu, A. Momeni and J. L. Lemaire, Astron. Astrophys., 2008, 492L, 17M.

5 T. Hama, K. Kuwahata, N. Watanabe, A. Kouchi, Y. Kimura, T. Chigai and V. Pirronello, Astrophys. J., 2012, 757, $185 \mathrm{H}$.

6 M. Minissale, E. Congiu, S. Baouche, H. Chaabouni, A. Moudens, F. Dulieu, G. Manicó and V. Pirronello, Chem. Phys. Lett., 2013, 565, 52.

7 K. Hiraoka, T. Miyagoshi, T. Takayama, K. Yamamoto and Y. Kihara, Astrophys. J., 1998, 498, 710.

8 D. C. B. Whittet, Dust in the Galactic Environment, 2nd edn, 2003.

9 K. I. Öberg, A. C. A. Boogert, K. M. Pontoppidan, S. van den Broek, F. van Dishoeck, E. S. Bottinelli, G. A. Blake and N. J. Evans, The Molecular Universe, Proceedings of the International Astronomical Union, 2011, p. 65.

10 S. B. Charnley, S. D. Rodgers and P. Ehrenfreund, Astron. Astrophys., 2001, 378, 1024-1036.

11 R. T. Garrod, S. L. W. Weaver and E. Herbst, Astrophys. J., 2008, 682, 283-302.

12 V. Wakelam, E. Herbst, J. Le Bourlot, F. Hersant, F. Selsis and S. Guilloteau, Astron. Astrophys., 2010, 517, A21.

13 E. Herbst and E. F. van Dishoeck, Annu. Rev. Astron. Astrophys., 2009, 47, 427-480.

14 H. Linnartz, J.-B. Bossa, J. Bouwman, H. M. Cuppen, S. H. Cuylle, E. F. van Dishoeck, E. C. Fayolle, G. Fedoseev, G. W. Fuchs, S. Ioppolo, K. Isokoski, T. Lamberts, K. I. Öberg, C. Romanzin, E. Tenenbaum and J. Zhen, The Molecular Universe, Proceedings of the International Astronomical Union, 2011, p. 390.

15 S. Ioppolo, H. E. Cuppen, C. Romanzin, E. F. van Dishoeck and H. Linnartz, Astrophys. J., 2008, 686, 1474.

16 F. Dulieu, L. Amiaud, E. Congiu, J.-H. Fillion, E. Matar, A. Momeni, V. Pirronello and J. L. Lemaire, Astron. Astrophys., 2010, 512, A30.

17 D. Jing, J. He, J. Brucato, A. De Sio, L. Tozzetti and G. Vidali, Astrophys. J., 2011, 741L, 9J. 
18 M. D. Ward and S. D. Price, Astrophys. J., 2011, 741, $121 \mathrm{~W}$. 19 Y. Oba, N. Watanabe, T. Hama, K. Kuwahata, H. Hidaka and A. A. Kouchi, Astrophys. J., 2012, 749, 67.

20 H. Chaabouni, M. Minissale, G. Manicó, E. Congiu, J. A. Noble, S. Baouche, M. Accolla, J. L. Lemaire, V. Pirronello and F. Dulieu, J. Chem. Phys., 2012, 137, 234706.

21 T. Lamberts, H. M. Cuppen, S. Ioppolo and H. Linnartz, Phys. Chem. Chem. Phys., 2013, 15, 8287L.

22 F. Dulieu, E. Congiu, J. Noble, S. Baouche, H. Chaabouni, A. Moudens, M. Minissale and S. Cazaux, Sci. Rep., 2013, 3, 1338 .

23 K. Hiraoka, A. Yamashita, Y. Yachi, K. Aruga, T. Sato and H. Muto, Astrophys. J., 1995, 443, 363.

24 H. Hidaka, M. Watanabe, A. Kouchi and N. Watanabe, Phys. Chem. Chem. Phys., 2011, 13, 15798.

25 E. Congiu, H. Chaabouni, C. Laffon, P. Parent, S. Baouche and F. Dulieu, J. Chem. Phys., 2012, 137, 054713.

26 G. Fedoseev, S. Ioppolo, T. Lamberts, J. F. Zhen, H. M. Cuppen and H. Linnartz, J. Chem. Phys., 2012, 137, 054714.

27 E. Congiu, G. Fedoseev, S. Ioppolo, F. Dulieu, H. Chaabouni, S. Baouche, J. Lemaire, C. Laffon, P. Parent, T. Lamberts, H. M. Cuppen and H. Linnartz, Astrophys. J., 2012, 750, L12.

28 P. R. Joshi, E. L. Zins and L. Krim, Mon. Not. R. Astron. Soc., 2012, 419, 1713.

29 H. Listz and B. Turner, Astrophys. J., 1978, L73, 224.

30 G. A. Blake, C. R. Masson, T. G. Phillips and E. C. Sutton, Astrophys. J., Suppl. Ser., 1986, 60, 357-374.

31 M. Gerin, Y. Viala, F. Pauzat and Y. Ellinger, Astron. Astrophys., 1992, 266, 463-478.

32 D. Halfen, A. J. Apponi and L. M. Zyrius, Astrophys. J., 2001, 561, 244.

33 M. Akyilmaz, D. R. Flower, P. Hily-Blant, G. Pineau des Forêts and C. M. Walmsley, Astron. Astrophys., 2005, 462, 221-230.

34 A. Nummelin, P. Bergman, A. Hjalmarson, P. Friberg, W. M. Irvine, T. J. Millar, M. Ohishi and S. Saito, Astrophys. J., Suppl. Ser., 2000, 128, 213-243.

35 D. J. Jansen, M. Spaans, M. R. Hogerheijde and E. F. van Dishoeck, Astron. Astrophys., 1995, 303, 541.

36 S. Martín, R. Mauersberger, J. Martín-Pintado, S. GarcíaBurillo and C. Henkel, Astron. Astrophys., 2003, 411, L465-L468.

37 G. Pineau des Forets, E. Roueff and D. R. Flower, Mon. Not. R. Astron. Soc., 1990, 244, 668-674.

38 L. Ottaviano, M. E. Palumbo, H. Rothard and G. Strazzulla, Conference Proceedings, 2000.
39 D. Sicilia, S. Ioppolo, T. Vindigni, G. A. Baratta and M. E. Palumbo, Astron. Astrophys., 2012, 453, A155.

40 P. Boduch, A. Domaracka, D. Fulvio, T. Langlinay, X. Y. Lv, M. E. Palumbo, H. Rothard and G. Strazzulla, Astron. Astrophys., 2012, 544, A30.

41 T. Millar, P. Farquhar and K. Willacy, Astron. Astrophys., Suppl. Ser., 1997, 121, 139.

42 S. Ioppolo, G. Fedoseev, T. Lamberts, C. Romanzin and H. Linnartz, Rev. Sci. Instrum., 2013, 84, 073112.

43 K. Acharyya, G. W. Fuchs, H. J. Fraser, E. F. van Dishoeck and H. Linnartz, Astron. Astrophys., 2007, 466, 1005A.

44 C. Romanzin, S. Ioppolo, H. M. Cuppen, E. F. van Dishoeck and H. Linnartz, J. Chem. Phys., 2011, 134, 4504R.

45 L. Amiaud, J.-H. Fillion, S. Baouche, F. Dulieu, A. Momeni and J. L. Lemaire, J. Chem. Phys., 2006, 124, 094702.

46 Z. Djouadi, L. D'Hendecourt, H. Leroux, A. P. Jones, J. Borg, D. Deboffle and N. Chauvin, Astron. Astrophys., 2005, 440, 179.

47 K. Tschersich, J. Appl. Phys., 1998, 845, 4065T.

48 K. Tschersich and V. von Bonin, J. Appl. Phys., 2000, 87, 2565T.

49 K. Tschersich, J. P. Fleischhauer and H. Schuler, J. Appl. Phys., 2008, 104, 034908.

50 A. Schmidt, J. Offermann and R. Anton, Thin Solid Films, 1996, 281, 105S.

51 R. Anton, T. Wiegner, W. Naumann, M. Liebmann, C. Klein and C. Bradley, Rev. Sci. Instrum., 2000, 71, 1177a.

52 W. G. Fateley, H. A. Bent and B. Crawford, J. Chem. Phys., 1959, 31, A30.

53 D. Fulvio, B. Sivaraman, G. Baratta, M. Palumbo and N. Mason, Spectrochim. Acta, 2009, 72, 1007.

54 M. E. Bartram and B. E. Koel, Surf. Sci., 1989, 213, 137.

55 U. Schwalke, J. E. Parmeter and W. H. Weinberg, J. Chem. Phys., 1986, 84, 4036.

56 A. Stirling, I. Papai, J. Mink and D. Salhub, J. Chem. Phys., 1994, 100, 2910.

57 M. Minissale, E. Congiu, S. Baouche, H. Chaabouni, A. Moudens, F. Dulieu, M. Accolla, S. Cazaux, G. Manicó and V. Pirronello, Phys. Rev. Lett., 2013, 111, 053201.

58 M. Minissale, E. Congiu and F. Dulieu, J. Chem. Phys., 2014, 140, 074705 .

59 NIST Chemistry WebBook, http:/webbook.nist.gov/chemistry/. 60 E. D. Glendening and A. M. Halpern, J. Chem. Phys., 2007, 127, 164307.

61 L. Amiaud, F. Dulieu, J.-H. Fillion, A. Momeni and J. L. Lemaire, J. Chem. Phys., 2007, 127, 144709. 